\title{
Blended Coatings from Polyaniline (PANI) and Chemically Doped Sodium Docecyl Benzene Sulphonate (SDBS)/SiO2 Nanocomposites: Influence on Corrosion Protection of Mild Steel
}

\section{N.Dhana Raj}

Central Institute of Plastics Engineering and Technology (CIPET), Chennai, Tamil nadu.

Smita Mohanty ( $\sim$ drsmitamohanty@gmail.com )

CIPET: Central Institute of Plastics Engineering and Technology https://orcid.org/0000-0002-36973272

Sanjay Nayak (Self-nomination)

Central Institute of Plastics Engineering and Technology (CIPET), Chennai, Tamil nadu.

\section{Research Article}

Keywords: PANI, Coating, Corrosion,nanocomposite

Posted Date: April 21st, 2021

DOl: https://doi.org/10.21203/rs.3.rs-442933/v1

License: (c) (1) This work is licensed under a Creative Commons Attribution 4.0 International License.

Read Full License 


\title{
Blended Coatings from Polyaniline (PANI) and Chemically doped Sodium

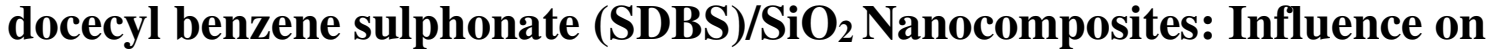 Corrosion Protection of Mild Steel

\author{
N.Dhana Raj ${ }^{1}$, SmitaMohanty ${ }^{2}$, S K Nayak ${ }^{1,2 *}$
}

Central Institute of Plastics Engineering and Technology (CIPET), Chennai, Tamil nadu. School for Advanced in Polymers (SARP) Laboratory for Advanced Research in Polymeric Materials (LARPM), CIPET Bhubaneswar, Odisha.

E Mail:drsknayak@yahoo.com

\begin{abstract}
In this work, investigation on corrosion protection performance of chemically synthesized polyaniline (PANI) / $\mathrm{SiO}_{2}$ nanocomposite coatings has been carried out on Mild Steel (MS). Sodium docecyl benzene sulphonate (SDBS) doped conducting PANI / $\mathrm{SiO}_{2}$ at different ratios was synthesized by employing in -situ polymerization technique. The developed coatings were characterized using Fourier transform infrared spectroscopy (FTIR), Thermo gravimetric analysis (TGA), Transmission electron microscopy (TEM), Contact angle, Atomic force microscopy (AFM) and corrosion analysis. The FTIR analysis indicates the strong interaction between PANI and $\mathrm{SiO}_{2}$ nanoparticles. The contact angle study reveals the hydophillicity character of the nanocomposite coatings with a water contact angle of 74.9 $9^{\circ}$ Corrosion resistanceof uncoated mild steel and the coated sample in $3.5 \% \mathrm{NaCl}$ aqueous solution has been evaluated using weight loss methods. Additionally the Electrochemical Impedance Spectroscopy (EIS) studies have been also conducted to evaluate the coorision protection characteristics of the coatings. PANI containing $\mathrm{SiO}_{2}$ (PSC III) coating showed excellent resistance after immersion in $3.5 \% \mathrm{NaCl}$ solution for 1 month time period.
\end{abstract}

Keywords: PANI, Coating, Corrosion,nanocomposite 


\section{INTRODUCTION:}

Corrosion process which involves gradual destruction of materials exposed to environmental conditions through chemical or electrochemical reactions has been a primary concern globally. Around 3\% of the global gross domestic product (GDP) annually is effected by the corrosion process[1-2].Corrosion protection employing polymeric coatings have generated considerable research interests in the recent years. Conducting polymers such as polypyrrole, polythiophene, polyaniline, polyacetylene etc. have been reported to be widely employed as coatings over the metal substrates to these substrates against corrosion [3-4]. Amongst the various conducting polymers, polyaniline (PANI) based systems have been reported to demonstrate improved corrosion protection properties as compared with the other polymers [3].

PANI known for its conducting properties [5] has good stability, high electrical conductivity [6] in addition to energy storage and electrochemical properties. PANI has been employed for multitude of applications like sensors, super capacitors, electrochromic display, fuel cells rechargeable organic batteries, drug delivery as well as in corrosion protection coatings. However, the major impediments of PANI includes limitations in processability predominantly due to its insolubility in majority of common solvents; brittle structure which prevents its wider applicability. These problems can be largely averted by changing the oxidation state of PANI, incorporation of dopants or preparing blends/composites of PANI with other polymers and reinforcing it with nanofillers[7].

Conducting polymer composites of PANI reinforced with nano fillers have been known to show its potentiality for corrosion protection. Encapsulated metal oxide based particles within the shell of PANI have bestowed improved physico-mechanical and chemical properties while retaining the conducting properties with synergism between the matrix polymer and the 
inorganic particles [8-9]. Several inorganic/organic particles like $\mathrm{SiO}_{2}, \mathrm{TiO}_{2}$, Graphene, $\mathrm{Fe}_{3} \mathrm{O}_{4}, \mathrm{ZnO}, \mathrm{ZnMoO}_{4}$ etc have been reinforced within PANI employing emulsion polymerisation technique to achieve desired attributes [10].

Among various inorganic particles, $\mathrm{SiO}_{2}$ nanoparticles having a porous structure can be suitably modified for its potential application in corrosion protection coatings [11]. AlDulaimi A et al have reported single step insitu method of synthesising PANI/SiO2 composite having improved corrosion protection characteristics in corrosive solvents [12]. Similar several reports pertaining to the anti-corrosive paints of $\mathrm{PANI} / \mathrm{SiO} 2$ have been reported by several workers havebeen reported [13-20].

In the current investigation $\mathrm{PANI} / \mathrm{SiO} 2$ nanocomposite coatings has been prepared using single step-in-situ-polymerisation technique. Sodium dodecyl benzene sulphonic acid (SDBS)was used as a dopant owing to its improved solubility. An in-depth study on the morphology of the synthesised nanocomposite coatings was carried out employing Fourier Transform Infrared spectroscopy (FTIR), Transmission electron microscopy, X-ray diffraction (XRD) and atomic force microscopy. The corrosion study was investigated through weigh loss method and the electrochemical impedance spectroscopy and contact angle study of the nanocomposite coatings have been reported.

\section{Experimental}

\subsection{Material}

Aniline procured from M/s NICE chemicals Pvt. Ltd, Kochi, Kerala, India and distilled prior to its use and stored at $10^{\circ} \mathrm{C}$. SDBS (Sodium Dodecyl Benzene Sulphonate), 1-methyl-2pyrrolidone (NMP), and APS (ammonium persulphate), were purchased from $\mathrm{M} / \mathrm{s}$ HimediaIndia. Nanosilica (175-225 m2/g[BET]) with $90 \%$ purity was purchased from M/s Sigma Aldrich USA. Epoxy clear with amine hardener (Finehard 486) was procured from 
M/s Fine finish organics Pvt ltd, Mumbai, India. Xylene, Sodium chloride (NaCl), 1-butanol and double distilled water were used for solution preparation. Stainless steel coupons for corrosion studies were purchased locally from Bhubaneswar, Odisha.

\subsection{Synthesis of PANI/ $\mathrm{SiO}_{2}$ Nanocomposite Coatings}

PANI/ $\mathrm{SiO}_{2}$ nanocomposite coatings were prepared using chemical oxidative using ammonium persulphate (APS) as the initiator in 1(M) $\mathrm{HCl}$ solution. In a four necked round bottom flask, $100 \mathrm{ml}$ solution comprising of $0.2 \mathrm{M}$ Aniline and $0.04 \mathrm{M}$ SDBS was taken to which $0.1 \mathrm{~g}$ of nano- $\mathrm{SiO}_{2}$ was added. Subsequently, 0.2 M APS was added drop wise and the reaction was carried out under nitrogen atmosphere for $3 \mathrm{~h}$ at $5^{0} \mathrm{C}$ in an ultrasonic bath to ensure complete the polymerization process. Nano-SiO $2:$ Aniline weight ratio was maintained at $0.10: 1(\mathrm{PANI} / \mathrm{SiO} 2-\mathrm{I})$. Then, the reaction mixture was kept at equilibrium state for $4 \mathrm{~h}$ and the final product obtained was filtered, washed with double distilled water till colorless filtrate was obtained and then dried at $60^{\circ} \mathrm{C}$ for $24 \mathrm{~h}$ in air oven. The aforesaid process was repeated to synthesize nanocomposites at variable weight ratios of $\mathrm{Nano}-\mathrm{SiO}_{2}$ :Aniline 0.15:1(PANI/SiO2-II) and 0.20:1(PANI/SiO2-III) respectively.

\subsection{Preparation of PANI/ SiOzcomposites coating on mild steel}

Mild steel panels were coated at variable loadings of PANI/SiO2(PSC) and neat PANI formulated with epoxy resin to evaluate the corrosion resistance properties of the coatings. Prior to coating the surface of the mild steel panels were subjected to gritting using emery paper followed by washing and cleaning with trichloroethylene and acetone to remove contamination if any on the surface. $6 \mathrm{~g}$ of solid epoxy resin was dissolved in $4 \mathrm{ml}$ xylene solution to which $1 \% \mathrm{PANI} / \mathrm{SiO}_{2}$ solution was added and ultrasonicated for $2 \mathrm{hrs}$. Then $1 \mathrm{~g}$ hardener was added and the mixture was further sonicated for $1 \mathrm{hr}$ to obtain the coating formulation. Xylene- butanol mixture at a ratio of 9:3 was added to maintain the viscosity of 
coating. Finally the coating formulation was coated onto mild steel substrate of $1 \mathrm{~cm}^{2}$ usingdrop coating method and was dried at $600{ }^{\circ} \mathrm{C}$ for $4 \mathrm{~h}$. A coating thickness of $110 \pm 10$ $\mu \mathrm{m}$ was maintained in all the formulations.

\subsection{Characterization of the PANI and its nanocomposite coatings}

After the successful growth of polymer nanocomposite coatings, the microstructural andelectrochemical corrosion properties were investigated using various characterization tools. Thestructural information of polymer nanocompositescoatings was performed using Fourier transforminfrared (FTIR) spectroscopy (Thermo Scientific, Nicolet 6700, USA) in the attenuated totalreflectance mode from $400-4000 \mathrm{~cm}^{-1}$. The X- ray diffraction pattern of the polymer nanocomposite coatings were examined using Shimadzu X-ray diffractometer with a measuringangle from 5 to $80^{\circ}$ and the scan rate was maintained $5 \% \mathrm{~min}$. The surface morphology of the polymernanocomposites was characterized by Transmission electron microscopy (TEM, 1400 JEOLJapan). Samples of $\sim 2 \mathrm{mg}$ was dispersed in $5 \mathrm{ml}$ of ethanol and sonicated for 5 mins to disperseuniformly. A drop dispersed solution was then placed on a copper grid and kept in the oven forcomplete dry or evaporate the sample. The surface topography and roughness of the coatingswere examined using Atomic Force Microscopy (AFM, XE-100). The measurements wereperformed in non-contact mode at room temperature. The wetting properties of the coatedsurface was acquired by contact angle measurement (Phoenix SEO Pvt. Ltd, Korea). The thermal stability of the samples was examined byThermogravimetric analysis (TGA) (M/s TA instruments, USA) at a heating rate of $10^{\circ} \mathrm{C} / \mathrm{min}$ in the temperature rangefrom 30 to $700{ }^{\circ} \mathrm{C}$ under nitrogen atmosphere.

\subsubsection{Electrochemical Impedance studies (EIS):}

The electrochemical characteristics of as-prepared epoxy and PS coatings were tested using a electrochemical workstation in $3.5 \% \mathrm{NaCl}$ solution. The exposed area of the coating 
is $1 \mathrm{~cm}^{2}$. The EIS and Tafel are measured in a three-electrode system. The coated substrate was a working electrode, saturated calomel electrode (SCE) was taken as reference electrode and platinum as a counter electrode. The following equations was used to evaluate the protection efficiency of the coating.

$$
\begin{aligned}
& P(\%)=\frac{R_{c t}-R_{c t}^{*}}{R_{c t}} \times 100 \\
& P(\%)=\frac{i_{c o r r}^{*}-i_{c o r r}}{i_{c o r r}^{*}} \times 100
\end{aligned}
$$

Where, $\mathrm{P}(\%)$ is the protection efficiency, $\mathrm{R}_{\mathrm{ct}}$ and $\mathrm{R}_{\mathrm{ct}} *$ is the charge transfer resistance of coated and uncoated substrate, $\mathrm{i}_{\text {corr }}$ and $\mathrm{i}_{\text {corr }} *$ is the corrosion current density coated and uncoated substrate.

\subsubsection{Weight loss method}

To further evaluate corrosion properties of as-prepared PANI/SiO2 coated mild steel was extensively studied by weight loss method. The bare and PANI/SiO2 coated mild steel

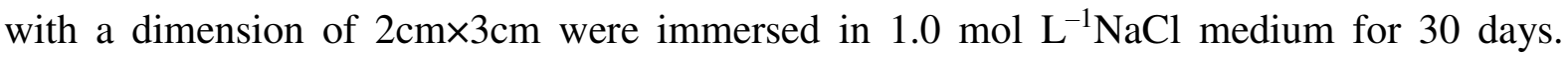
Before and after immersion, the bare and coated mild steel were weighed in the electronic balance. After 30 days, the test specimens were removed from the solution and washed exhaustively withdistilledwater, followed by acetone and dried in air. The changes in the coated substrate were visually inspected after 30 days of immersion. Moreover, the changes in weight were calculated according to the weight loss $\left(\mathrm{g} \mathrm{cm}^{-2} \mathrm{~h}^{-1}\right)$ formula as follows

$$
W_{L}=\frac{W_{1}-W_{2}}{a t}
$$

The corrosion rate (CR) of the PS coated mild steel substrate was estimated by weight loss method using the following equation.

$$
C R\left(\text { mmyear }^{-1}\right)=\frac{\left(W_{1}-W_{2}\right) \times 87.6}{\text { atd }}
$$


Where, $\mathrm{W}_{1}$ is the initial weight (before immersion) of the sample $(\mathrm{mg}), \mathrm{W}_{2}$ final weight (after immersion) of the sample $(\mathrm{mg})$, $\mathrm{a}$ is the surface area of the sample $\left(\mathrm{cm}^{2}\right), \mathrm{t}$ is the end time of immersion (h) and $\mathrm{d}$ is the density of bare mild steel substrate $\left(7.85 \mathrm{~g} \mathrm{~cm}^{-3}\right)$.

\section{Results \& Discussion}

\subsection{FTIR analysis}

Fig 1. Represents the FTIR spectra of PANI Neat and PANI/SiO2 nanocomposites, respectively. The peak corresponding to1575 and $1483 \mathrm{~cm}^{-1}$ represented thestretching vibration of $\mathrm{C}=\mathrm{N}$ and $\mathrm{C}=\mathrm{C}$ in all the samples. Thebandsat $1292 \mathrm{~cm}^{-1}$ and1245 $\mathrm{cm}^{-1}$ confirmed the $\mathrm{C}-\mathrm{N}$ stretching mode of the benzenoid ring. The peak at $1118-1112 \mathrm{~cm}-{ }^{1}$ assigned to $\mathrm{C}-\mathrm{H}$ modein plane bending vibration during protonation [21]. The FTIR spectrum corresponding to the presence of $\mathrm{SiO}_{2}$ was observedat $1061 \mathrm{~cm}^{-1}$ and $807 \mathrm{~cm}-{ }^{1}$ attributed to the stretching and bending vibrations of $\mathrm{Si}-\mathrm{O}-\mathrm{Si}$, respectively. The $\mathrm{C}-\mathrm{N}$ stretching vibration in protonic acid doped PANI from PANI-SDBS, where $\mathrm{SO}^{3-}$ group of SDBS is bounded with the nitrogen atom of PANI was observed at $1302 \mathrm{~cm}^{-1}$. Further in the case of PSC there was shift of peaks to higher wavenumbers at $1565 \mathrm{~cm}^{-1}, 1483 \mathrm{~cm}^{-1}, 1292 \mathrm{~cm}^{-1}$ and $1245 \mathrm{~cm}^{-1}$ respectively as compared with neat PANI due to the dispersion of silica nanoparticles in the matrix. Similarly, thebending vibration of $\mathrm{Si}-\mathrm{O}-\mathrm{Si}$ peak at $1056 \mathrm{~cm}-{ }^{1}$ was found to be shifted to lower wavenumbers. The behaviours indicated interaction between PANI and $\mathrm{SiO}_{2}$ nanoparticles. 


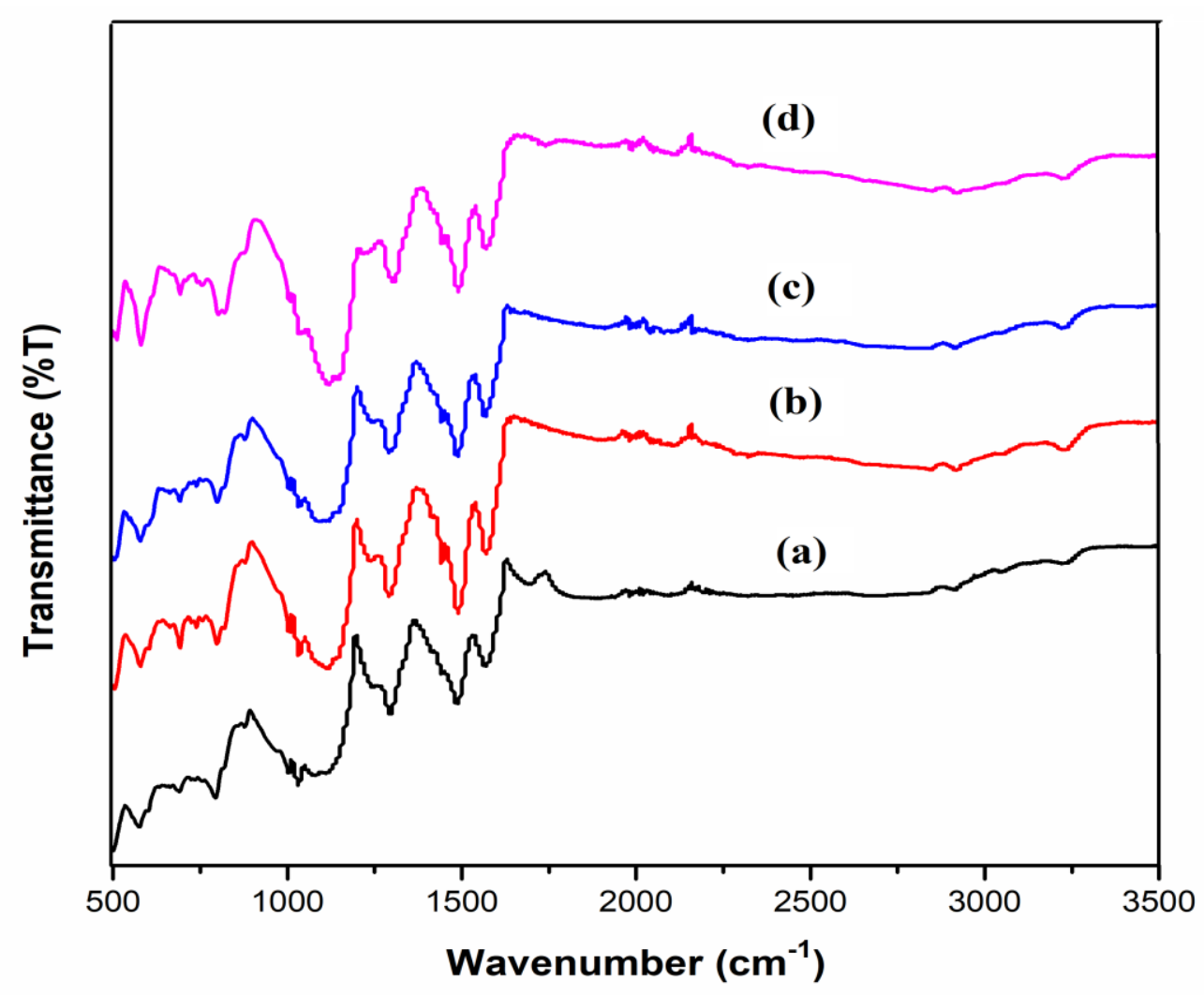

Fig 1. FT-IR spectra of (a) PANI neat, (b)PSC-I, (c)PSC-II, and (d)PSC-III

\subsection{XRD analysis}

The XRD pattern of PANI and PANI/ SiO2is representedin Fig 2. The peak related to PANI was observed at $2 \theta=20$ and $25^{\circ}$, indicating (020) (200) semi-crystalline planes as reported by Chin et al. [22]. However, with the incorporation of SDBS, the intensity of the d200 peak reduced in presence of dopant. Further as observed from the x-ray diffractograms of $\mathrm{PANI} / \mathrm{SiO} 2$ nanocomposite it is observed that a relatively intense peak at $2 \theta=20$ was observed which revealed higher crystalline nature of PANI in presence of the dopant and $\mathrm{SiO} 2$.

On contrary, Chei et al. [22], had reported in their work that $\mathrm{SiO}_{2}$ has no influence on the crystallinity of PANI. Hence, it can be concluded that addition of $\mathrm{SiO}_{2}$ has considerable effect on PANI and that might due to the absorption of PANI on $\mathrm{SiO}_{2}$ surface in presence of SDBS [23]. 


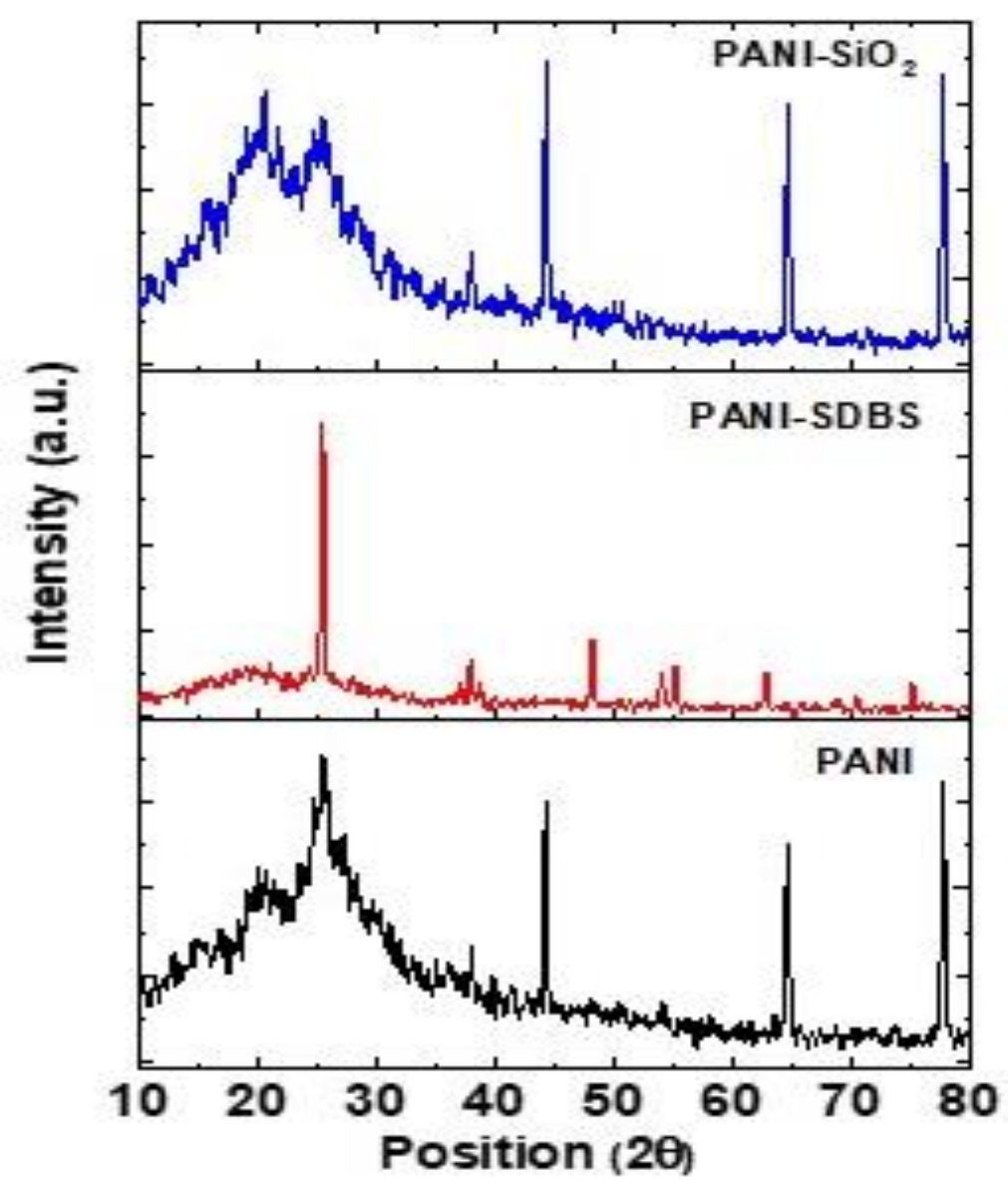

Fig.2. XRD pattern of neat PANI, PANI-SDBS and its nano composites

\subsection{TEM Studies}

Fig 3 shows the TEM image of $\mathrm{PANI} / \mathrm{SiO}_{2}$ composites. From the figure, it is clear that the $\mathrm{SiO}_{2}$ nanoparticles are uniformly distributed in the PANI matrix. This uniform distribution of $\mathrm{SiO}_{2}$ in the composite may be due to the incorporation of SDBSthat acts as dispersant and might be held responsiblefor the control ofhomogeneity in the composite. The agglomerated structure of PSC also found due to interparticle interaction of $\mathrm{SiO}_{2}$. Further,a portion of the micrograph has been found to be dark indicating the thickness of the sample was too high for TEM imaging due to mass contrast phenomena. 


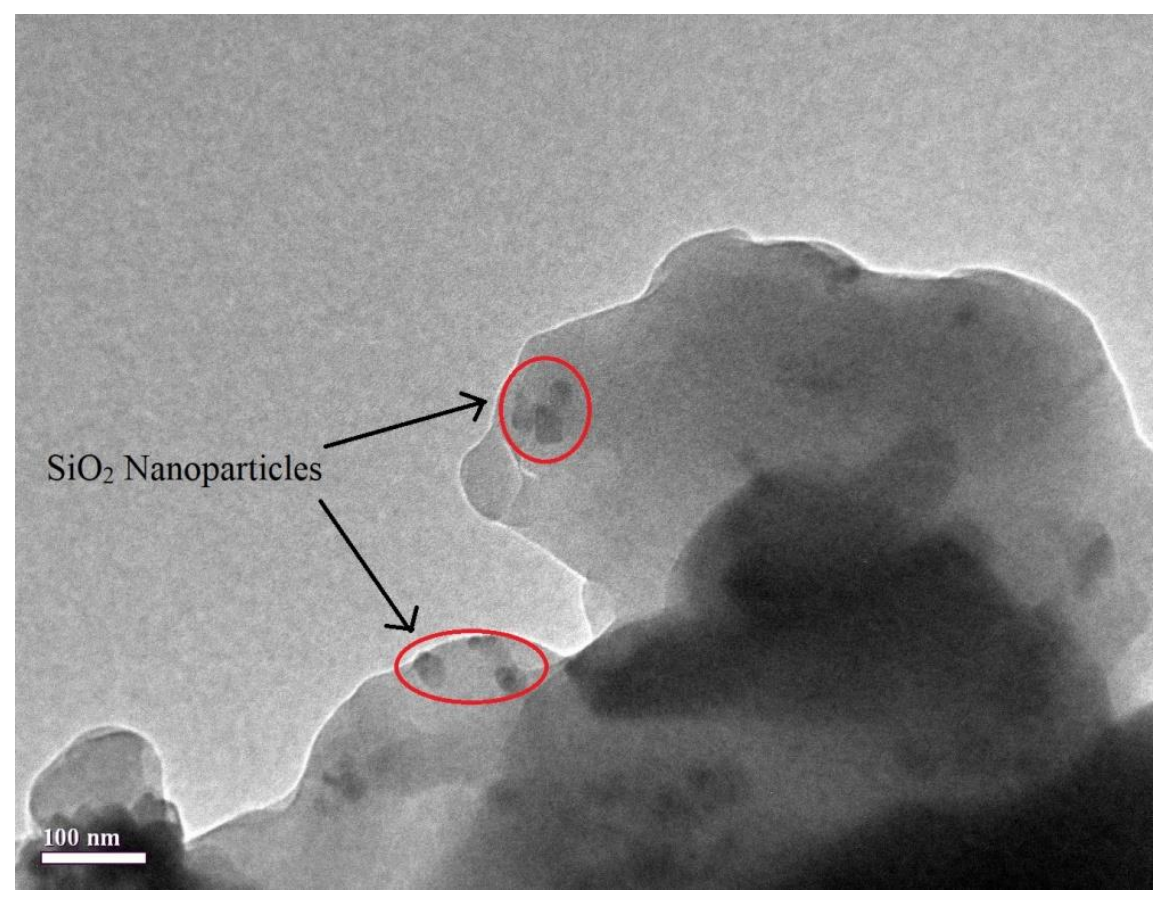

Fig 3. TEM image of PANI/ $\mathrm{SiO} 2$ composites

\subsection{AFM studies}

The surface morphology of PANI neat and PSC thin films were characterized by Atomic Force Microscopy technique. Figures 4 (a) and (b) shows the 3D Atomic Force Microscopic images of PANI neat and PSC respectively. .

As observed from the AFM micrographs the $\mathrm{SiO} 2$ nanopartices were dispersed uniformly within the PANI matrix. Also it may be noted that the nanocompositesample displayedincreasing root-mean-square (RMS) surface roughness value of $16.06 \mathrm{~nm}$ as compared withneat PANI which had an RMS value of 5.87. 

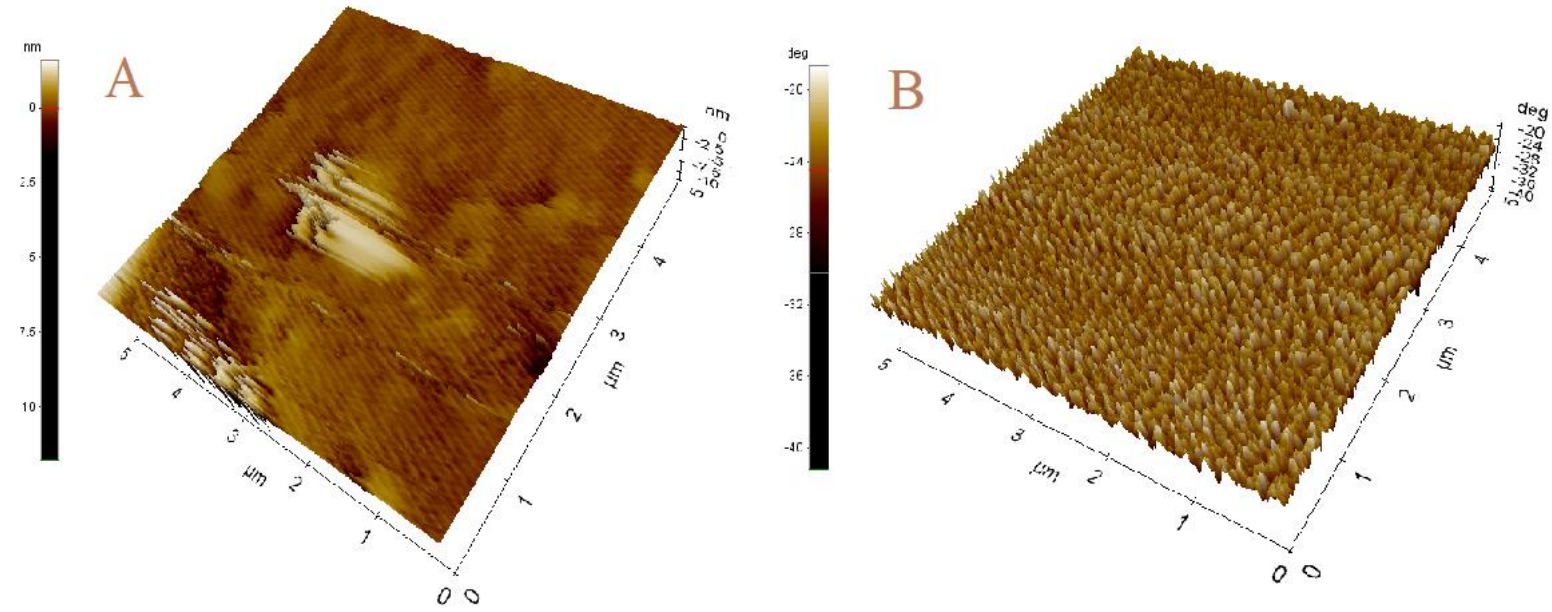

Fig 4. 3D Atomic Force Microscopic images of (a) PANI neat and (b) PANI/SiO2-III

\subsection{Contact angle}

This wettability characteristics of the coated surfaces was testedusing contact angle measurements. The data of water contact angle measurements showed that the surface paint had shown fig 5. The hydrophilic nature because the contact angle is less than 90 degree. The measurements revealed that the surface contact angle of PANI Neat and PANI/SiO $2-\mathrm{III}$ nanoomposite was found to be $64^{\circ}$ and $73^{\circ}$, respectively asshown in Fig.5. This shows an improvement of thePANI/SiO${ }_{2}$ in the wettability characteristics as compared to the neat counterpart. Therefore the results indicate that the incorporation of $\mathrm{SiO}_{2}$ reduces the hydrophillicity.

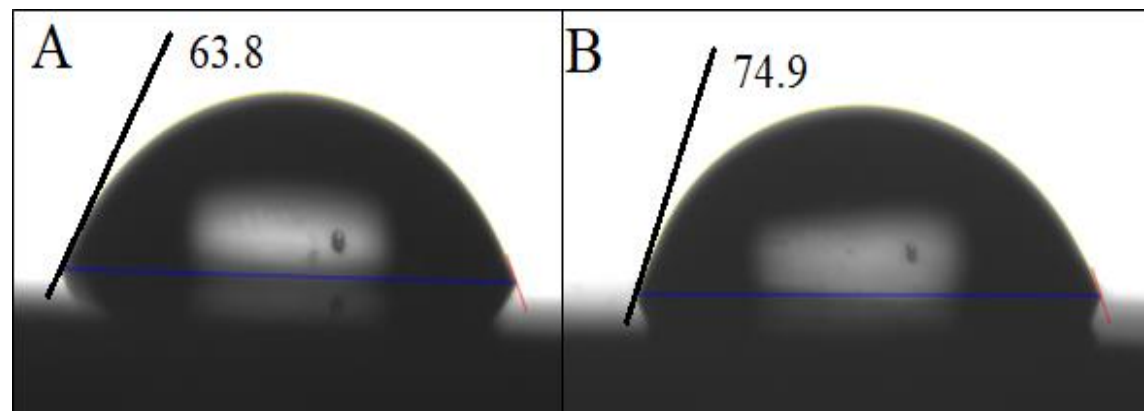

Fig 5. Contact angle of (A) PANI Neat, (B) PANI/SiO 2 composite 


\subsection{TGA Studies}

TGA thermograms of PANI Neat, and PANI/ $\mathrm{SiO}_{2}-\mathrm{III}$ nanocomposites are depicted in Fig. 6. As observed from the thermogramsPANI Neat displayed (Fig.6) athree decomposition. The initial decomposition observed at $240^{\circ} \mathrm{C}$ with a corresponding weight loss of about 3-10\% may be attributed to the loss of residual water trapped in the PANI matrix and other volatiles. The decomposition in the second stage at 310 to $450{ }^{\circ} \mathrm{C}$ involves the loss of dopant SDBS as well as the initial degradation of the backbonethe matrix polymer.The third stage decomposition observed beyond $570^{\circ} \mathrm{C}$ indicated the degradation of both SDBVS and PANI. $\mathrm{SiO}_{2}$ nanoparticles have thermal stability up to $800^{\circ} \mathrm{C}$. Thus, incorporation of $\mathrm{SiO}_{2}$ within the PANI matrix improved the thermal stability which is predominantly due to the barrier layer formed by the nanoparticles that prevent outflow of the decomposition of products [24].

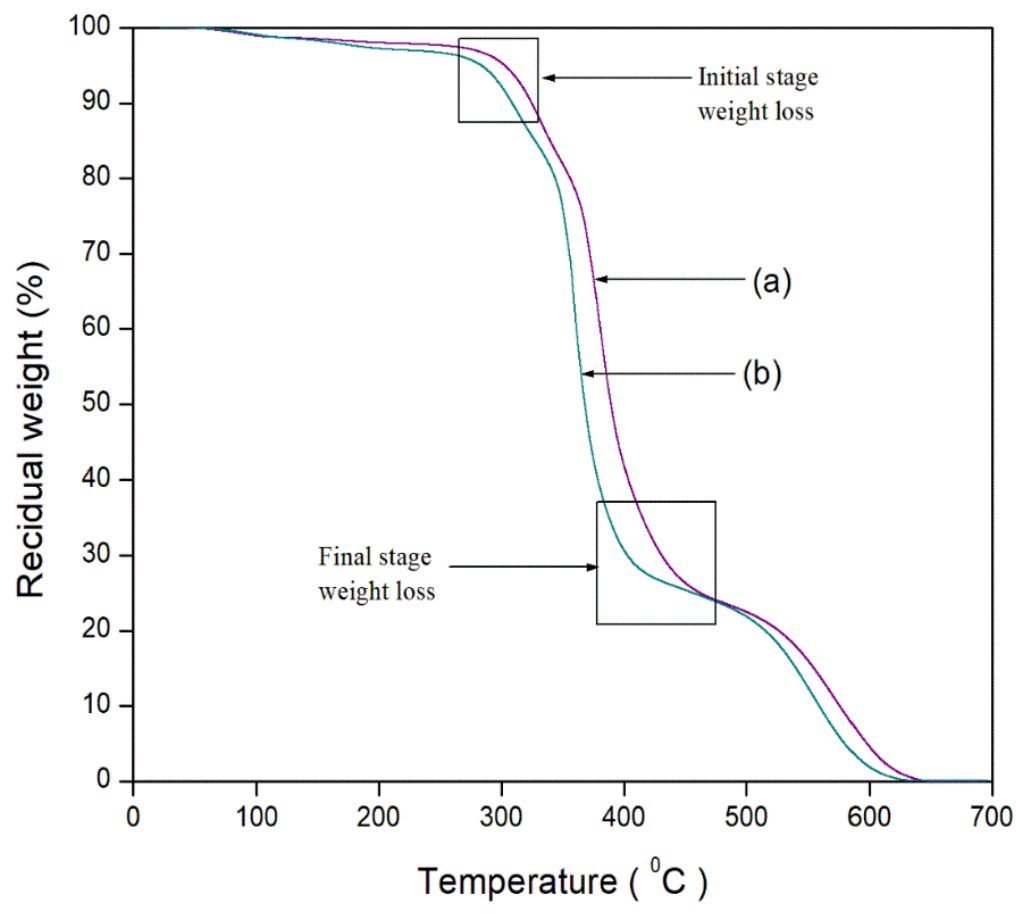

Fig 6. TGA Curves of (a) PANI Neat, (b) $\mathrm{PANI} / \mathrm{SiO}_{2}$ composite 


\subsection{Corrosion studies (weight loss method)}

Table 1. Weight loss parameter during the immersion test in $3.5 \% \mathrm{NaCl}$ for 30 days

\begin{tabular}{|c|c|c|c|c|c|}
\hline Sample name & $\begin{array}{c}\text { Initial } \\
\text { weight } \\
\text { (mg) }\end{array}$ & $\begin{array}{c}\text { Weight after } \\
\text { immersion } \\
3.5 \% \text { NaCl for } 30 \\
\text { days }\end{array}$ & $\begin{array}{c}\text { Weight } \\
\text { loss (mg) }\end{array}$ & $\begin{array}{c}\text { Weight loss } \\
(\%)\end{array}$ & $\begin{array}{c}\text { Corrosion } \\
\text { rate } \\
\text { (mm/year) }\end{array}$ \\
\hline $\begin{array}{c}\text { Blank Milid } \\
\text { Steel }\end{array}$ & 4283.1 & 3669.76 & 613.34 & 14.32 & 1.59 \\
\hline $\begin{array}{c}\text { Epoxy } \\
\text { (Blank) }\end{array}$ & 4783.6 & 4227.26 & 556.34 & 11.63 & 1.44 \\
\hline PANI neat & 4967.5 & 496.58 & 470.92 & 9.48 & 1.21 \\
\hline PANI/SiO2III & 4769.1 & 4531.60 & 237.50 & 4.98 & 0.61 \\
\hline PANI/SiO2 -I & 4872.8 & 4456.66 & 416.14 & 8.54 & \\
\hline & 4678.3 & 4373.28 & 305.02 & 6.52 & \\
\hline & & & & & \\
\hline
\end{tabular}

The corrosion rates(CR) in mm/year of blank mild steel, epoxy blank, PANI Neat and $\mathrm{PANI} / \mathrm{SiO} 2$ is represented in Table 1 . As observed from the table the weight loss $\%$ in blank mild steel was $14.32 \%$ which reduced to $11.63 \%$ after coating with epoxy. Further in case of PANI coated samples the weight loss was $9.38 \%$ in $3.5 \%$ NaCL after 30 days time period. 
However, the PANI/SiO2 coated panels showed improved performance in which the weight loss was $4.98 \%$. Comparing the CR rates, it is evident from the test results reported in Table 1 , after 30 days of immersion of the blank mild steel, the CR value was 1.59 /year which reduced drastically to $0.61 \mathrm{~mm} /$ year approximately to the tune of $160 \%$ thus revealing the efficacy of the coated nanocomposite panels [21].

\section{Electrochemical studies of PS/MS Coatings}

The corrosion properties of as-prepared coatings were analyzed by EIS and Tafel techniques in $3.5 \% \mathrm{NaCl}$ solution. The Tafel curves acquired for the mild steel, epoxy coating and PANI-SiO 2 epoxy coating were shown in Fig 7. The corrosion potential and current density of the blank and coated substrates were obtained from the Tafel curves by the intersection of the extrapolation of anodic and cathodic curves. The calculated electrochemical parameters were given in the Table 2. It is observed that the PS/MS coatings showed improved corrosion resistance compared to the epoxy coatings and bare substrate by decreasing the corrosion current density $\left(\mathrm{I}_{\mathrm{corr}}\right)$ and the shift toward the positive side in corrosion potential $\left(\mathrm{E}_{\mathrm{corr}}\right)$. Moreover, the PS/MS coatings revealed higher protecting efficiency of $90 \%$ compared to other coatings and substrates. 


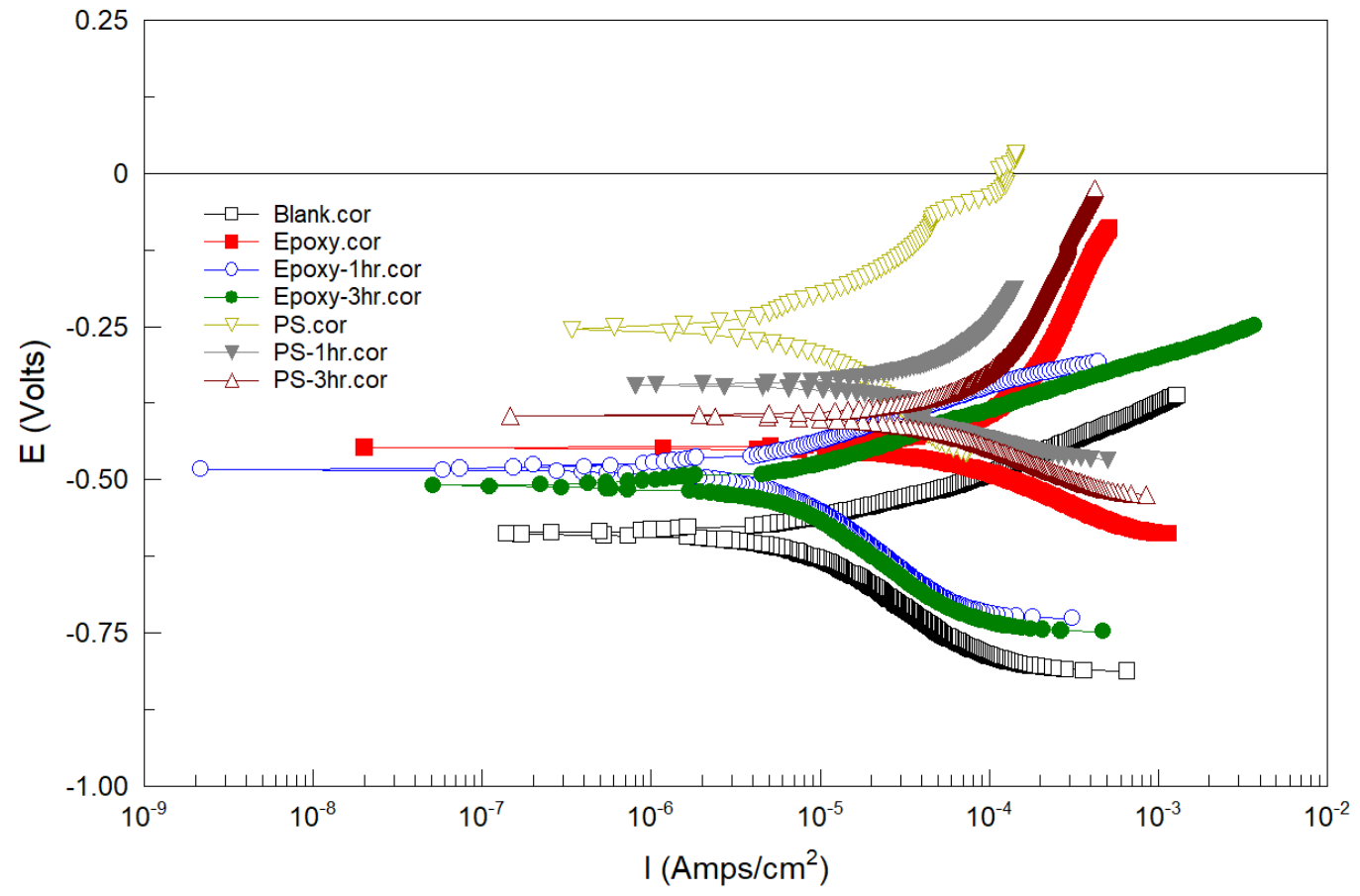

Figure. 7 Electrochemical properties of mild steel, epoxy and PS coatings.

The charge transfers resistance and capacitance of the blank and as-prepared coatings were tested by electrochemical impedance spectroscopy. The bode profiles of the mild steel, epoxy coating and PANI-SiO 2 epoxy coatings were displayed in Fig 8. From the curve, it is observed that the increase in charge transfer resistance and decrease in capacitance indicates the better corrosion resistance property of as-prepared PS/MS coatings over epoxy and bare substrate. Moreover, from the periodic evolution, the PS coatings provide better corrosionresistant performance than epoxy coating. However, a decrease in performance when increasing the immersion time it might be due to the slightly porous nature of the coating induces the corrosion phenomena. The results demonstrate that the PS coating itself has a barrier and redox property, which improves corrosion protection performance. 


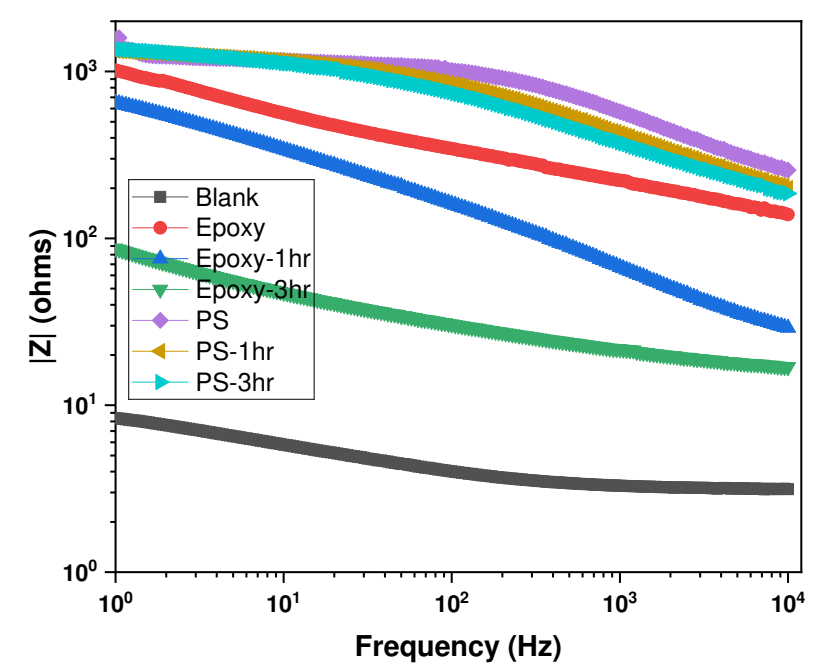

Figure 8. Bode plots of mild steel, epoxy and PS coatings.

Table:2Protection performance of PS and Epoxy coatings on steel in $3.5 \% \mathrm{NaCl}$

\begin{tabular}{|l|c|c|c|c|c|c|}
\hline \multirow{2}{*}{ Samples } & \multicolumn{3}{|c|}{ EIS } & \multicolumn{3}{c|}{ Tafel } \\
\cline { 2 - 7 } & $\begin{array}{c}\boldsymbol{R}_{\mathbf{c t}} \\
\mathbf{\Omega} \mathbf{c m}^{2}\end{array}$ & $\begin{array}{c}\boldsymbol{C}_{\mathbf{d l}} \\
\boldsymbol{\mu} \mathbf{F} / \mathbf{c m}^{2}\end{array}$ & $\begin{array}{c}\text { Protection } \\
\text { Efficiency } \\
(\%)\end{array}$ & $\begin{array}{c}\text { Icorr } \\
\boldsymbol{\mu} \mathbf{A} / \mathbf{c m}^{2}\end{array}$ & $\begin{array}{c}\boldsymbol{E}_{\mathbf{c o r r}} \\
\mathbf{m V} \mathbf{~ v s} \\
\mathbf{S C E}\end{array}$ & $\begin{array}{c}\text { Protection } \\
\text { Efficiency } \\
(\%)\end{array}$ \\
\hline Blank & 4.9 & 32 & -- & 564 & -588 & - \\
\hline Epoxy0 hr & 547 & 22 & 99 & 92 & -447 & 83 \\
\hline Epoxy 1 hr & 141 & 11 & 96 & 80 & -482 & 85 \\
\hline Epoxy 3 hr & 91 & 18 & 94 & 82 & -505 & 85 \\
\hline PS 0 hr & 1262 & 707 & 99 & 54 & -253 & 90 \\
\hline PS 1 hr & 1191 & 161 & 99 & 93 & -364 & 82 \\
\hline PS 3 hr & 470 & 369 & 98 & 78 & -395 & 86 \\
\hline
\end{tabular}




\section{CONCLUSION}

PANI / $\mathrm{SiO}_{2}$ nanocomposites have been successfully prepared by situ solution polymerization in aqueous solution containing SDBS as a dopant with different weight ratios of $\mathrm{SiO}_{2} /$ aniline. The synthesis and curing of the composites were confirmed by spectral studies. Contact angle analysisindicate the increase in contact angle value due to the incorporation of $\mathrm{SiO}_{2}$. TGA results revealed that inclusion of $\mathrm{SiO}_{2}$ nanoparticles improves the thermal stability of composite to a smaller extent due to the interaction of $\mathrm{SiO}_{2}$ particles and PANI matrix. TEM images of nanocomposites showed the polymer growth on the surface of $\mathrm{SiO}_{2}$ particles. AFM studies indicate the surface roughness value can be increasing by incorporation $\mathrm{SiO}_{2}$ nanocomposites. Corrosion study shows that PANI and $\mathrm{PANI} / \mathrm{SiO}_{2}$ nanocomposites coating show good corrosion resistance property on mild steel in $3.5 \% \mathrm{NaCl}$ aqueous solution. The results also revealed that corrosion protection property depends on $\mathrm{SiO}_{2}$ content in composite coating and better corrosion resistance is observed for the formulation containing $0.20 \mathrm{SiO}_{2}$ (PSCIII).

\section{References}

1. A. Stierle, Tracking corrosion cracking. Science 321, 349-350 (2008)

2. F U. Renner, et al. Initial corrosion observed on the atomic scale. Nature 439, 707710 (2006)

3. Q. Wang, B.W. Zhang, M.N. Qu, J.Y. Zhang, D.Y. He. Appl. Surf. Sci. 2008; 254: 2009

4. JC. Lacroix, JL. Camalet, S. Aeiyach, KI. Chane-Ching, J. Petitjean, E.Chauveau, Electroanal. Chem 2000; 481:76.

5.AG.Mac Diarmid, J C.Chiang, and A F.Richter, Synth Met 18 (1987) 28

6. A K.Bakhshi, and G J .Bhalla, Sci Ind Res 63-715 (2004)

7.G M Spinks, A J Dominis, G G Wallace, and D E Tallman, Solid State Electrochem 6 85 (2002). 
8.M Angelopoulos, IBM J RES \& DEV 45-57 (2001).

9. P K Khanna, M V Kulkarni, N Singh, S P Lonkar, V VVV SSubharao, and A K Visvanath, Mater ChemPhys 95 (2006).

10. G Majumdar, M Goswami, TK Sarma, A Paul,and A Chattopadhyay, Langmuir 21:1663(2005).

11. D Chowdhury, A Paul, and A Chattopadhyay,Langmuir21:4123(2005).

12. XM Feng, G Yang, WH Hou, and Zhu JJ, Macromol Rapid Commun 27:31(2006).

13. Al-Dulaimi, and S Hashim, Int. J. Mech. Mater. Eng. 7113 (2012)

14.M Hasan, Y Zhou, S Mahfuz and S Jeelani, Mater Sci Eng A 429: 181 (2006)

15. Li X, Dai, G Wang and X Song Appl Polym Sci 107:403 (2008)

16. HS Xia, and Q Wang, Appl Polym Sci 87:1811 (2003).

15. H Zengina, and B Erkan, Polym Adv Technol 21:216 (2010)

18. H Bhandari, V Choudhary, and SK Dhawan, Thin Solid Films, 519: 1031 (2010)

19. J IIribarren, E Armelin, F Liesa, J Casanovas, and CAleman 57: 683 (2006).

20. KS Rao, KEl-Hami, T Kodaki, K Matsushige and K Makino, J Colloid Interface Sci 289:125(2005)

21. S. Hema Bhandari, S. Anoop Kumar and, K. Dhawan Chapter http://dx.doi.org/10.5772/50470, 2012

22. S. Y. Chin, T. K. Abdullah, · M. Mariatti, J Mater Sci: Mater Electron (2017)

23.R C Rathod, V K Didolkar, S S Umare, and B H Shambharkar, Trans Indian Inst Met 43-64 (2011)

24. M Rohwerder, L Duc,A Michalik, Coatings. Electrochem. Acta54, 6075-6081 (2009) 
Figures

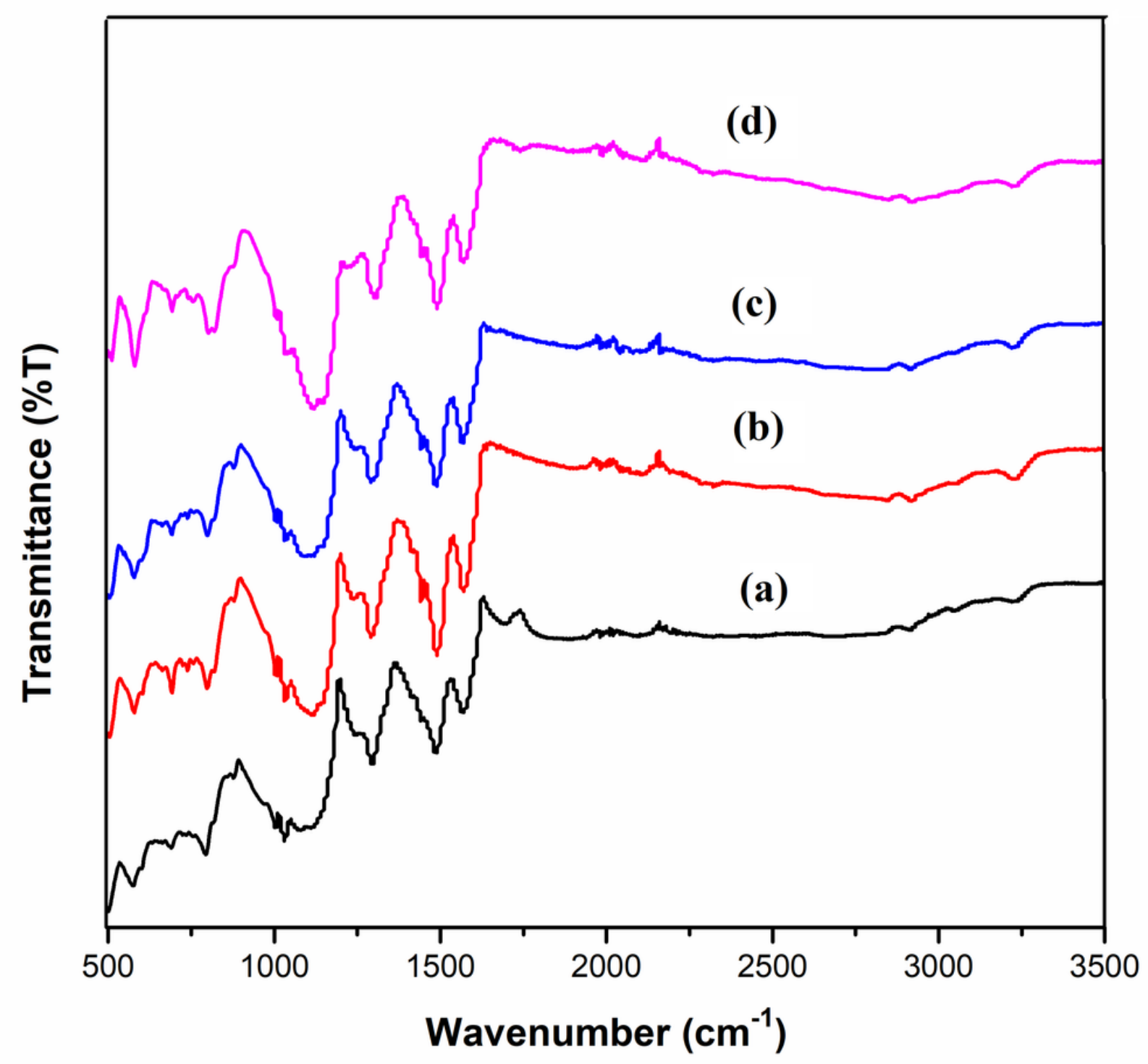

Figure 1

FT-IR spectra of (a) PANI neat, (b)PSC-I, (c)PSC-II, and (d)PSC-III 


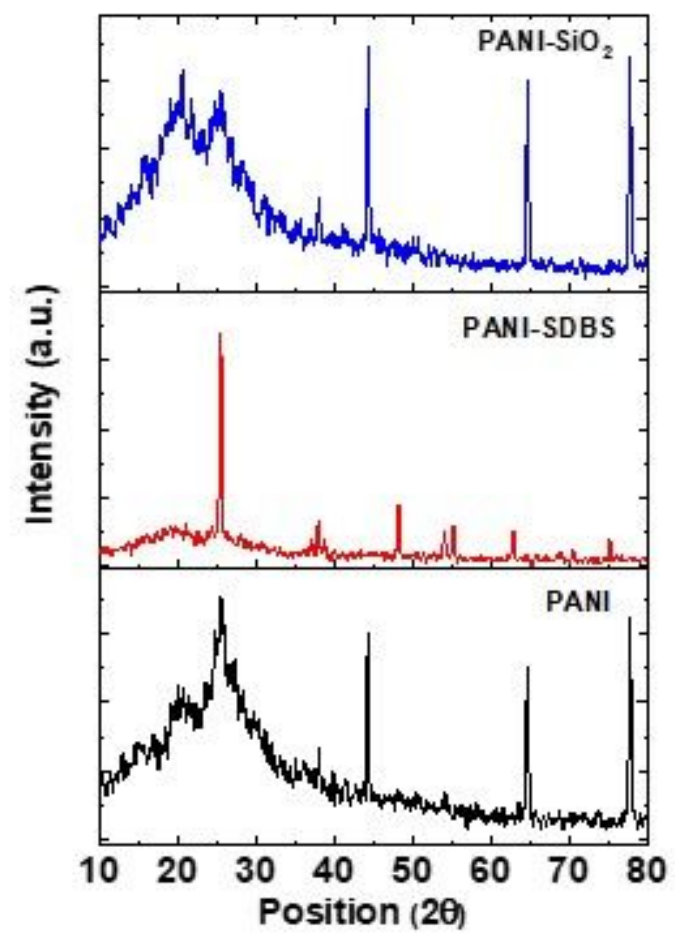

Figure 2

XRD pattern of neat PANI , PANI-SDBS and its nano composites 


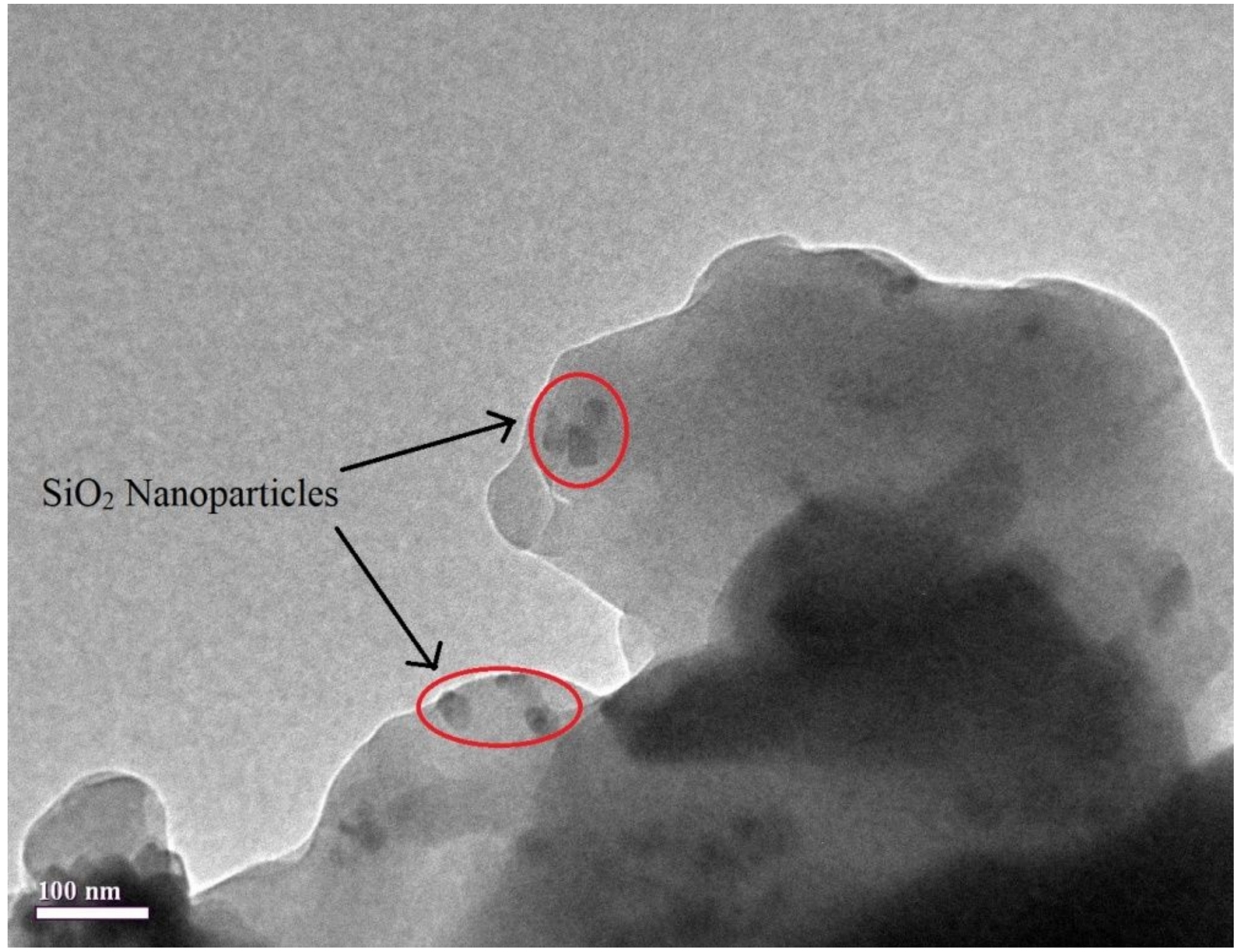

Figure 3

TEM image of PANI/ SiO2 composites 

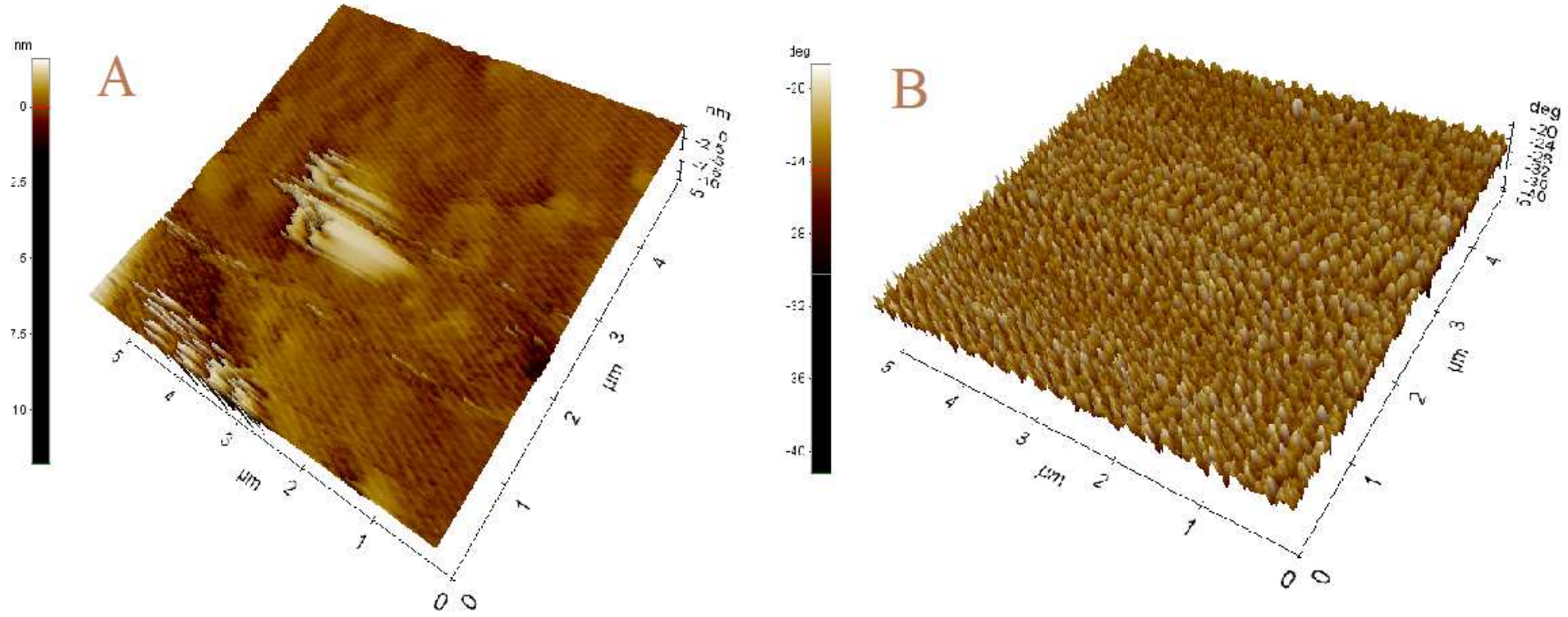

Figure 4

3D Atomic Force Microscopic images of (a) PANI neat and (b) PANI/SiO2-III

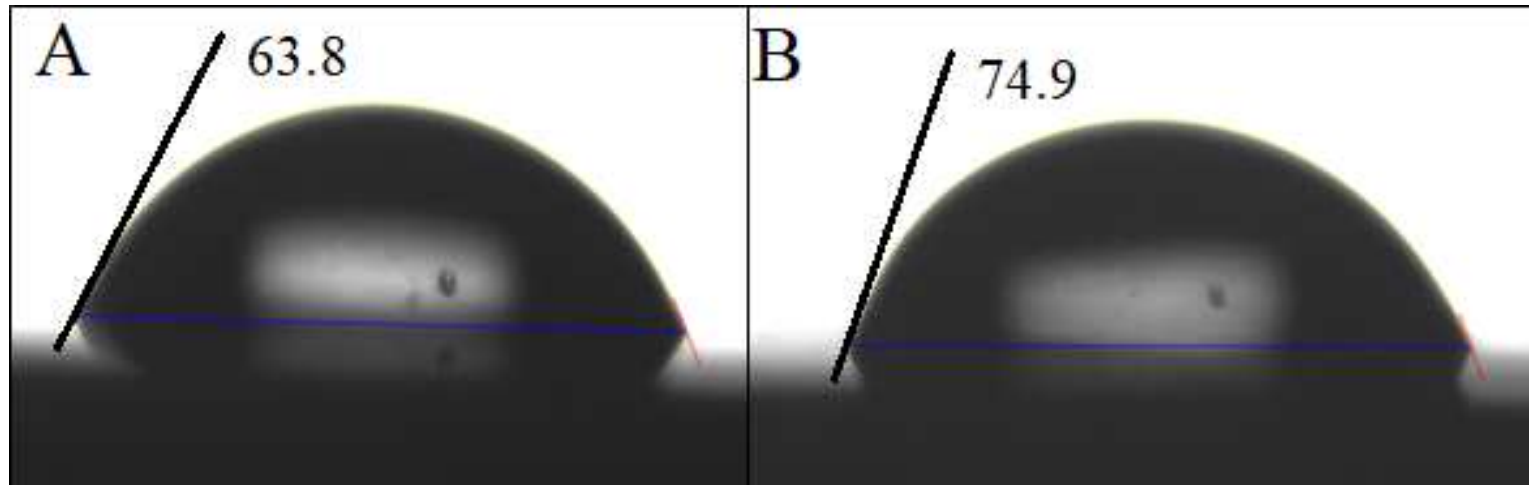

Figure 5

Contact angle of (A) PANI Neat, (B) PANI/SiO2 composite 


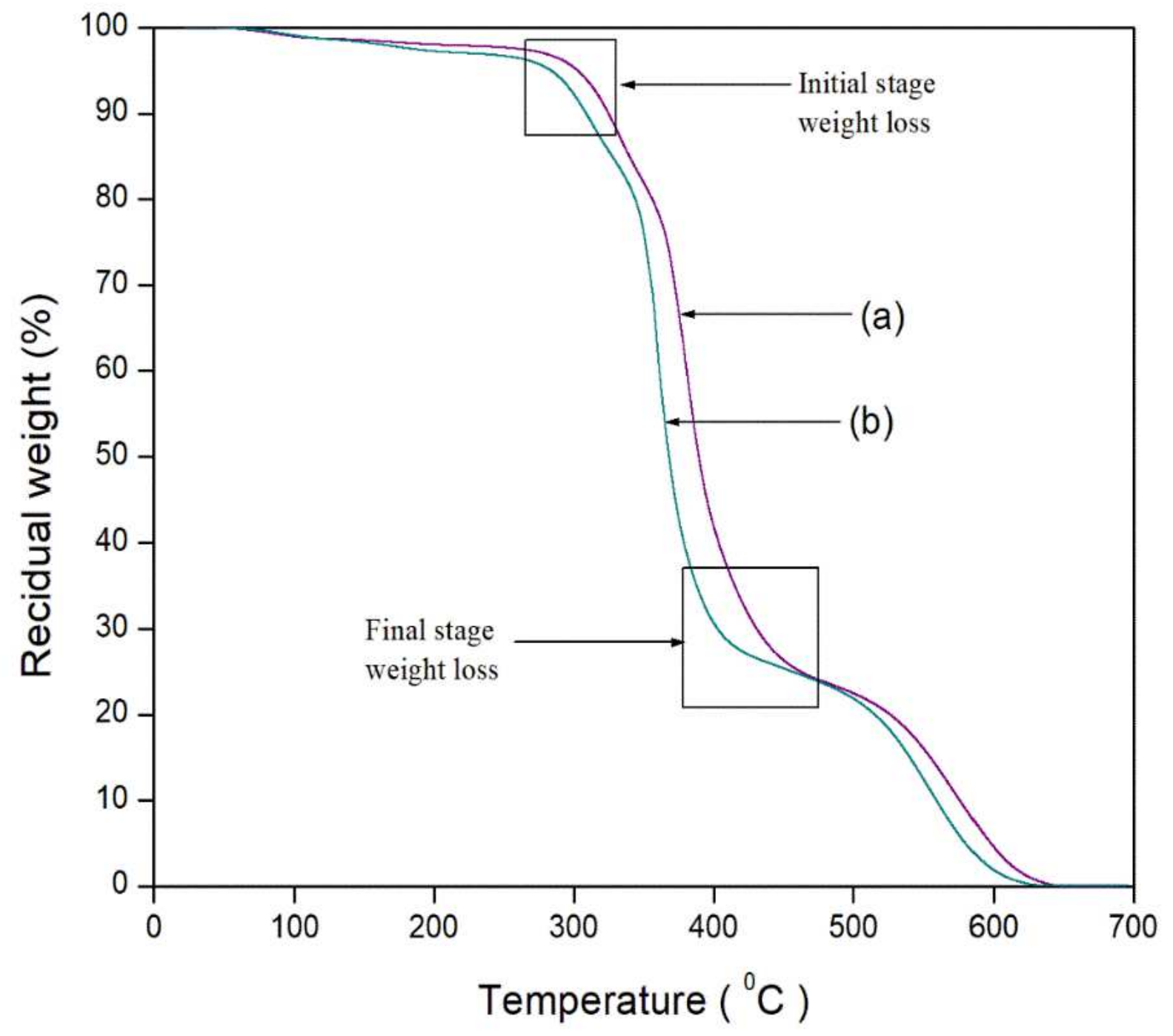

Figure 6

TGA Curves of (a) PANI Neat, (b) PANI/SiO2 composite 


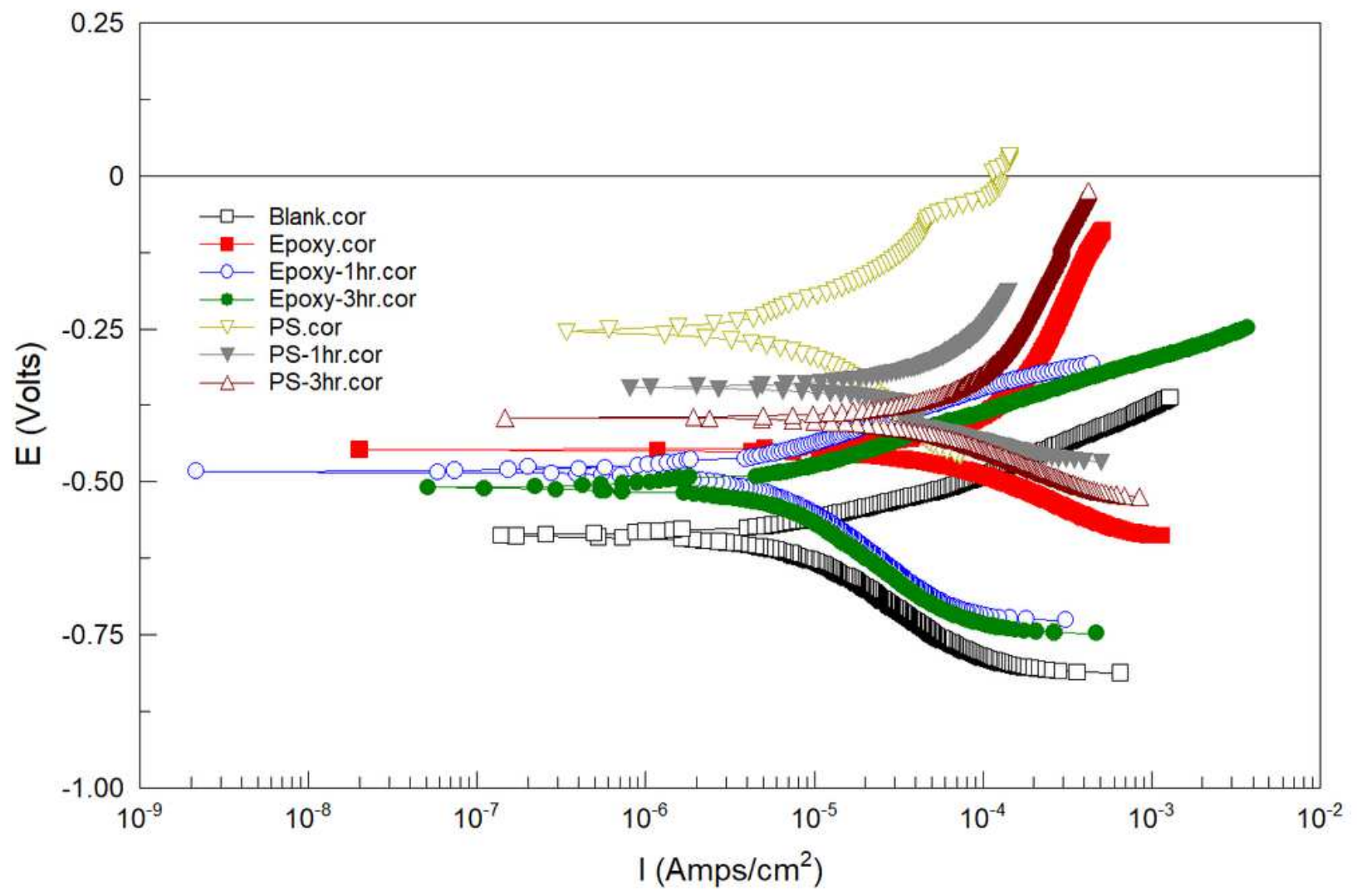

Figure 7

Electrochemical properties of mild steel, epoxy and PS coatings. 


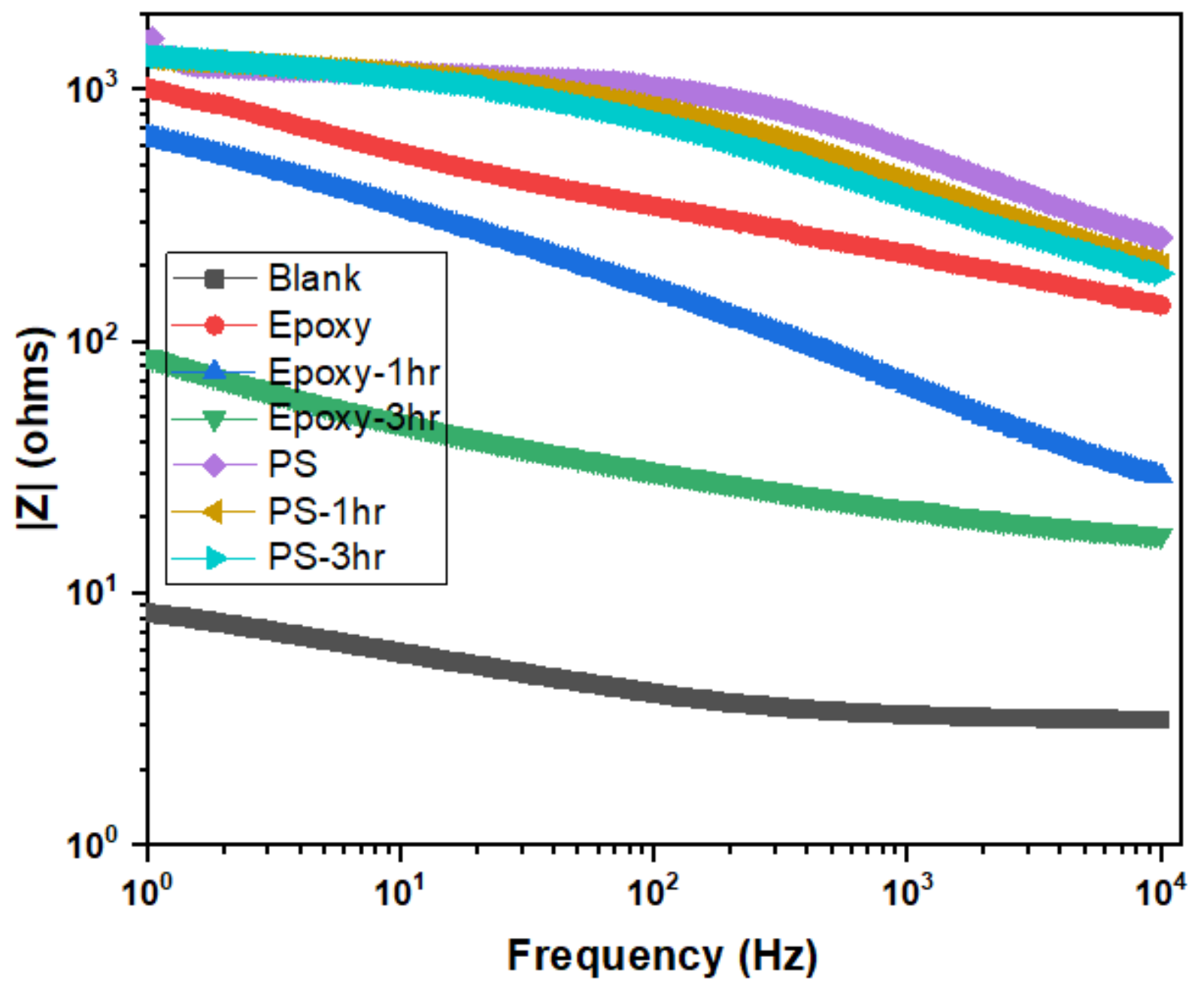

Figure 8

Bode plots of mild steel, epoxy and PS coatings. 